\title{
Cholinergic correlates of cognitive impairment in Parkinson's disease: comparisons with Alzheimer's disease
}

\author{
ELAINE K PERRY, ${ }^{*}$ MICHAEL CURTIS, $\dagger$ DAVID J DICK, $\ddagger$ JOHN M CANDY, $\S$ \\ JOHN R ATACK,${ }^{*}$ CLIVE A BLOXHAM,${ }^{*}$ GARRY BLESSED,$\|$ ANDREW FAIRBAIRN, ${ }^{* *}$ \\ BERNARD E TOMLINSON, ${ }^{*}$ ROBERT H PERRY§
}

\begin{abstract}
From the Department of Neuropathology, Newcastle General Hospital; * Department of Pathology, Royal Victoria Infirmary; $†$ Regional Neurological Centre, Newcastle General Hospital; $\ddagger$ MRC Neuroendocrinology Unit, Newcastle General Hospital; § Psychogeriatric Unit, Newcastle General Hospital\| and St Nicholas Hospital, Newcastle Upon Tyne, ${ }^{* *}$ UK
\end{abstract}

summary Dementia in Parkinson's disease has previously been attributed to the presence in the cerebral cortex of Alzheimer-type neuropathological abnormalities. New evidence suggests, however, that dementia in this disease usually occurs in the absence of substantial Alzheimertype changes in the cortex and may be related to abnormalities in the cortical cholinergic system. Thus, in Parkinsonian patients with dementia there were extensive reductions of choline acetyltransferase and less extensive reductions of acetylcholinesterase in all four cortical lobes. Choline acetyltransferase reductions in temporal neocortex correlated with the degree of mental impairment assessed by a test of memory and information but not with the extent of plaque or tangle formation. In Parkinson's but not Alzheimer's disease the decrease in neocortical (particularly temporal) choline acetyltransferase correlated with the number of neurons in the nucleus of Meynert suggesting that primary degeneration of these cholinergic neurons may be related, directly or indirectly, to declining cognitive function in Parkinson's disease.

Evidence of an involvement of the transmitter, acetylcholine, in memory ${ }^{12}$ has stimulated investigation of the cholinergic system in disorders of the human brain affecting memory and other cognitive functions. An abnormality of the cholinergic system in Alzheimer-type dementia is now well established and correlations between the severity of the disease (assessed either neuropathologicallly or clinically) and reductions in the cortical cholinergic enzyme, choline acetyltransferase (CAT), have been reported. ${ }^{34}$ Dementia or cognitive impairment also occurs in a significant number of patients with Parkinson's disease (for review, see reference 5) and several reports have attributed the dementia to the presence of Alzheimer-type cortical neuropathology in these cases. ${ }^{67}$

Address for reprint requests: Dr EK Perry, Dept of Neuropathology Research, Newcastle General Hospital, Westgate Rd, Newcastle upon Tyne, NE4 6BE, UK.

Received 14 February 1984 and in revised form 3 October 1984. Accepted 10 October 1984.
The condition of the cortical cholinergic system in Parkinson's disease is unclear since some groups have reported, in cases not assessed for mental function, normal CAT activities $^{89}$ whereas another group has reported CAT reductions correlating with the degree of dementia assessed retrospectively. ${ }^{10}$ With respect to the condition of the principal cholinergic nucleus innervating the neocortex-the nucleus of Meynert-there is evidence that loss of neurons occurs in both Parkinson's and Alzheimer's disease. "12 Whether this neuronal degeneration in both diseases is closely associated with the cortical cholinergic abnormalities (assessed biochemically) is unclear although this issue is relevant to the question of whether subcortical cholinergic abnormalities represent primary or secondary features of the disease processes.

The present investigation was undertaken primarily to examine the relationship between, on the one hand, cognitive impairment or dementia in Parkinson's disease and, on the other hand, the presence of cortical cholinergic abnormalities, cortical 
Table 1 Case details

\begin{tabular}{|c|c|c|c|c|c|}
\hline \multirow[t]{2}{*}{ Clinical category } & \multirow[t]{2}{*}{ Normal } & \multicolumn{2}{|l|}{ Parkinson's disease } & \multirow{2}{*}{$\begin{array}{l}\text { Combined Parkinson's } \\
\text { and Alzheimer's disease }\end{array}$} & \multirow{2}{*}{$\begin{array}{l}\text { Alzheimer } \\
\text { disease }\end{array}$} \\
\hline & & (a) Mentally normal & (b) Mentally impaired & & \\
\hline $\begin{array}{l}\text { Number of cases } \\
\text { Age (years) } \dagger \\
\text { Gender (males: females) } \\
\text { Postmortem interval (h) } \dagger\end{array}$ & $\begin{array}{c}8 \\
79 \pm 8 \\
4: 4 \\
26 \pm 7\end{array}$ & $\begin{array}{l}4 \\
74 \pm 10 \\
1: 3 \\
24 \pm 17\end{array}$ & $\begin{array}{l}7 \\
72 \pm 7 \\
5: 2 \\
25 \pm 15\end{array}$ & $\begin{array}{l}3 \\
77 \pm 13 \\
0: 3 \\
17 \pm 8\end{array}$ & 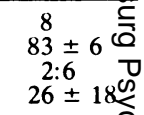 \\
\hline $\begin{array}{l}\text { Neocortical plaque count } \dagger \text { (mean } \\
\text { number/ } 1.3 \mathrm{~mm} \text { diameter field) } \\
\text { Neocortical neurofibrillary tangles } \\
\text { Test scores }\end{array}$ & $\begin{array}{l}5 \cdot 7 \pm 4 \cdot 0 \\
\text { Absent } \\
-\end{array}$ & $\begin{array}{l}7 \cdot 6 \pm 8 \cdot 4 \\
\text { Absent } \\
\text { - }\end{array}$ & $\begin{array}{l}6 \cdot 2 \pm 7 \cdot 1 \\
\text { Absent } \\
18 \pm 10(5)\end{array}$ & $\begin{array}{l}34 \cdot 0 \pm 9 \cdot 8 \\
\text { Present } \\
2,13\end{array}$ & $\begin{array}{l}22 \cdot 1 \pm \underset{\text { Present }}{\text { Prest }} \\
12 \pm 5\end{array}$ \\
\hline $\begin{array}{l}\text { Meynert nucleus neuron count } \dagger \\
\text { (mean cell number/20 u section) }\end{array}$ & $162 \pm 26$ & $134 \pm 37(4)$ & $45 \pm 34(3)$ & 41 & $149 \pm 36$ 胥 \\
\hline
\end{tabular}

${ }^{*}$ Memory and information test of Blessed et al, $1968^{14}$

† Mean values \pm standard deviation.

Alzheimer-type pathology and Meynert neuron loss. Comparisons with Alzheimer's disease are included and show that although cortical cholinergic biochemical activities are almost identical in Parkinsonian and Alzheimer-type dementia, the neuropathological involvement of the neocortex and Meynert nucleus generally distinguishes between the two disorders. Thus, Parkinsonian intellectual deficit, but not Alzheimer-type dementia, is invariably accompanied by neuron loss in the nucleus of Meynert whereas the presence of neocortical neurofibrillary tangles and numerous senile plaques are virtually confined to Alzheimer's disease. A preliminary report of some of these findings has been published. ${ }^{13}$

\section{Subjects and methods}

Cases

Case details are provided in table 1. Eight control cases, with no neurological or psychiatric symptoms (age range 63 to $89 \mathrm{yr}$ ), 14 cases with Parkinson's disease (age range 62 to $80 \mathrm{yr}$ ) and eight cases of Alzheimer's disease (age range 73 to 92 yr) were examined at necropsy between 5 and 48 hours post mortem. Amongst the Parkinsonian cases, cognitive impairment was present in 10 . Recent mental test scores, ${ }^{14}$ available for seven, ranged from 0 to 27 out of a maximum possible score of 37 . The remaining four Parkinsonian cases were not known to have had an established dementing syndrome during life. In two of the ten cognitively impaired Parkinsonian cases a dementing syndrome was a major feature in the initial psychiatric presentation. Extrapyramidal symptoms were not prominent in these two cases and the presentation, although not entirely typical of Alzheimer's disease, included memory impairment, right left disorientation, agnosia, constructional apraxia, and nominal aphasia. However, subsequent neuropathological examination (see below) indicated a diagnosis of Parkinson's rather than Alzheimer's disease The eight Alzheimer-type cases fulfilled clinical ant pathological criteria previously described ${ }^{14-16}$ and, a $\$$ judged by available test scores and cortical plaque $\vec{\omega}$ densities, were generally moderate rather than severes cases.

\section{Neuropathological Assessment}

Following removal of samples for biochemical analyse (see below) the remaining left and intact right hemispheres were subjected to standard macro- and microscopie ${ }^{+}$ examination. ${ }^{1516}$ In all 14 of the Parkinsonian cases, but neither the normal nor Alzheimer groups, both cell loss and Lewy body formation were evident in the dopaminergic cells of the substantia nigra. With respect to Alzheimer-type pathological changes in the cortex, neurofibrillary tangles were absent and the senile plaque density (table 1$)$ was within the normal range ${ }^{15}$ ( 0 to 14 mean plaques per $1.3 \mathrm{~mm}^{2}$ ) for this age group in the normal cases and 11 of the 14 Parkinsonian cases. In the three

Table 2 Cholinergic activities $\ddagger$ in human brain

\begin{tabular}{|c|c|c|c|c|c|}
\hline Clinical category & $\begin{array}{l}\text { Choline Acetyltro } \\
\text { (nmol/h/mg prot } \\
\text { occipital }\end{array}$ & $\begin{array}{l}\text { isferase } \\
\text { n) } \\
\text { parietal }\end{array}$ & temporal & entorhinal & frontal \\
\hline $\begin{array}{l}\text { Normal } \\
\text { Parkinson's diceace }\end{array}$ & $3 \cdot 50 \pm 1 \cdot 27$ & $6.09 \pm 1.37$ & $4.64 \pm 1.93$ & $8.63 \pm 3.61$ & $8.61 \pm 2.65 \frac{2}{3}$ \\
\hline $\begin{array}{l}\text { (a) mentally normal } \\
\text { (b) mentally impaired } \\
\text { Combined Parkinson's and Alzheimer's disease } \\
\text { Alzheimer's disease }\end{array}$ & $\begin{array}{l}1.44 \pm 0.39 \dagger \\
0.91 \pm 0.31 \dagger \\
* 0.97 \pm 0.72 \\
1.42 \pm 0.60 \dagger\end{array}$ & $\begin{array}{l}2.98 \pm 0.30 \dagger \\
1 \cdot 31 \pm 0.89 \dagger \S \\
2 \cdot 18 \pm 1 \cdot 78 \\
1.08 \pm 0.85 \dagger\end{array}$ & $\begin{array}{l}3 \cdot 22 \pm 1 \cdot 52 \\
1 \cdot 21 \pm 1 \cdot 13+1 \\
0 \cdot 56 \pm 0.32 \\
1 \cdot 10 \pm 0.67 \dagger\end{array}$ & $\begin{array}{l}7.67 \pm 1.94 \\
2.94 \pm 0.66+\| \\
\frac{1.91}{} \pm 1.18 \dagger\end{array}$ & 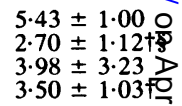 \\
\hline
\end{tabular}

*, †Significantly different (Student's t-test) from the normal $(p<0.01$ and $<0.001)$.

¥Activities as mean \pm standard deviation.

\&l|Significant difference between the two Parkinsonian sub-groups $(p<0.05$ in temporal cortex and $p<0.01$ in the remaining areas), nonenof differences between sub-group (b) and the group with Alzheimer's disease reached significance.

** Statistics not performed on this group of 3 cases. 
remaining cases of Parkinson's disease, all of which were cognitively impaired, the plaque count ( 23 to 41 per $1 \cdot 3$ $\mathrm{mm}^{2}$ ) and presence of neocortical neurofibrillary tangles were diagnostic of co-existing Alzheimer's disease. Amongst the seven cognitively impaired Parkinsonian cases without co-existing Alzheimer's disease, the plaque density was in the upper normal range (13 to 14 per 1.3 $\mathrm{mm}^{2}$ ) in three, including the two cases (see above) presenting primarily with a dementing disorder. In none of these three cases with a relatively high plaque density were neocortical tangles identified.

The neuron numbers in the nucleus of Meynert were estimated in basal forebrain tissue (the substantia innominata) dissected and paraffin embedded from the formalin fixed left hemisphere as previously described. ${ }^{11}$ Serial sections $20 \mu \mathrm{m}$ thick were cut through the entire region and, at $500 \mu \mathrm{m}$ intervals or less, the total number of Meynert neurons (with a diameter greater than $25 \mu \mathrm{m}$ and containing a nuclear nucleolus) were counted (excluding neurons adjacent to the diagonal band) between the levels of the mid anterior commissure and the coronal level of the mammillary body." From these counts the average number of neurons per section was calculated. In selected cases frozen tissue from the left temporal lobe was stained histochemically for acetylcholinesterase .(AChE) using techniques described elsewhere. ${ }^{17}$

\section{Biochemical analysis}

At necropsy, samples of tissue were removed from the four cortical lobes of the left hemisphere (Brodmann areas: 10, $21,28,40$ and 19) and stored in liquid nitrogen. For biochemical analysis small portions of grey matter were homogenized in 10 volumes of $0.32 \mathrm{M}$ sucrose containing $0.5 \%$ Triton X-100 and assayed for CAT, AChE and protein as previously described. ${ }^{3}$ Analysis of the molecular forms of the enzyme $\mathrm{AChE}$ was carried out on parietal cortex, extracted and separated by sucrose density gradient centrifugation, as previously described. ${ }^{18}$

\section{Results}

The different clinical categories (table 1) were matched for age and post mortem delay. In all four cortical lobes of the cognitively impaired Parkinsonian cases there were reductions of CAT (table 2). In those Parkinsonian cases without clinically established cognitive impairment, CAT activities were less reduced and only significantly different from the normal in occipital and parietal cortex. Comparing the mentally normal and impaired Parkinsonian subgroups, CAT activity in the latter was significantly lower than the former in all areas except occipital cortex. In the cases with combined Parkinson's and Alzheimer's disease the enzyme loss was generally similar to that in the separate groups of demented Parkinson's and Alzheimer's disease. In the latter group there were CAT reductions in all areas although interestingly these were, with the possible exception of entorhinal cortex (Brodmann area 28), no greater than in the mentally impaired Parkinsonian cases, despite the lesser degree of dementia in the latter (table 1).

Similar although less marked changes were evident from the data on acetylcholinesterase activities (table 2). Thus, there were in frontal, temporal and parietal cortex losses of AChE in the Parkinsonian group with dementia. This trend did not reach significance in occipital cortex and in parietal cortex there was no apparent distinction between this group and the mentally normal Parkinsonian group. The distinction between the mentally normal and impaired Parkinsonian subgroups was generally less marked for AChE, compared with CAT, and only reached significance in entorhinal and frontal cortex. As for CAT, AChE losses in the cases of combined Parkinson's and Alzheimer's disease and in pure Alzheimer disease cases were generally similar to those in the demented Parkinsonian subgroup. Furthermore, in the latter group there was an extensive and selective loss of one molecular form of $\mathrm{AChE}$ - the intermediate $10 \mathrm{~S}$ form (fig 1). In the three demented Parkinsonian cases analysed, this form was reduced to $17 \%$ of the normal level whilst the lower (3.7S) and higher (16S) molecular weight forms were unaffected. Histochemically a loss of cortical and white matter AChE positive cholinergic fibres in a cognitively impaired Parkinsonian case is illustrated in fig $2 \mathrm{a}$ and a lesser reduction in a case of non-demented Parkinson's disease in fig $2 \mathrm{~b}$.

In view of the relationship known to exist in Alzheimer's disease between the loss of cortical CAT and extent of neuropathological abnormalities such as plaques ${ }^{3}$ or tangles, ${ }^{4}$ the relation between CAT loss and plaque density in the Parkinsonian

\begin{tabular}{|c|c|c|c|c|}
\hline $\begin{array}{l}\text { Acetylcholinesterase } \\
(\text { ( } \mathrm{mol} / \mathrm{h} / \mathrm{mg} \text { protein }) \\
\text { occipital }\end{array}$ & parietal & temporal & entorhinal & frontal \\
\hline $0.56 \pm 0.20$ & $0.95 \pm 0.41$ & $0.68 \pm 0.15$ & $1 \cdot 18 \pm 0.45$ & $0.86 \pm 0.17$ \\
\hline $\begin{array}{l}0.38 \pm 0.11 \\
0.39 \pm 0.18 \\
0.43 \pm 0.13 \\
0.46 \pm 0.14\end{array}$ & $\begin{array}{l}0.48 \pm 0.14^{*} \\
0.45 \pm 0.09^{*} \\
0.69 \pm 0.28 \\
0.46 \pm 0.15^{*}\end{array}$ & $\begin{array}{l}0.58 \pm 0.13 \\
0.41 \pm 0.17^{*} \\
0.31 \pm 0.23 \\
0.40 \pm 0.12^{*}\end{array}$ & $\begin{array}{l}1.23 \pm 0.32 \\
0.73 \pm 0.21^{*} \S \\
\frac{0.58}{} \pm 0.32 *\end{array}$ & $\begin{array}{l}0.70 \pm 0.08 \\
0.44 \pm 0.10 \dagger 8 \\
0.66 \pm 0.75 \\
0.52 \pm 0.18^{*}\end{array}$ \\
\hline
\end{tabular}




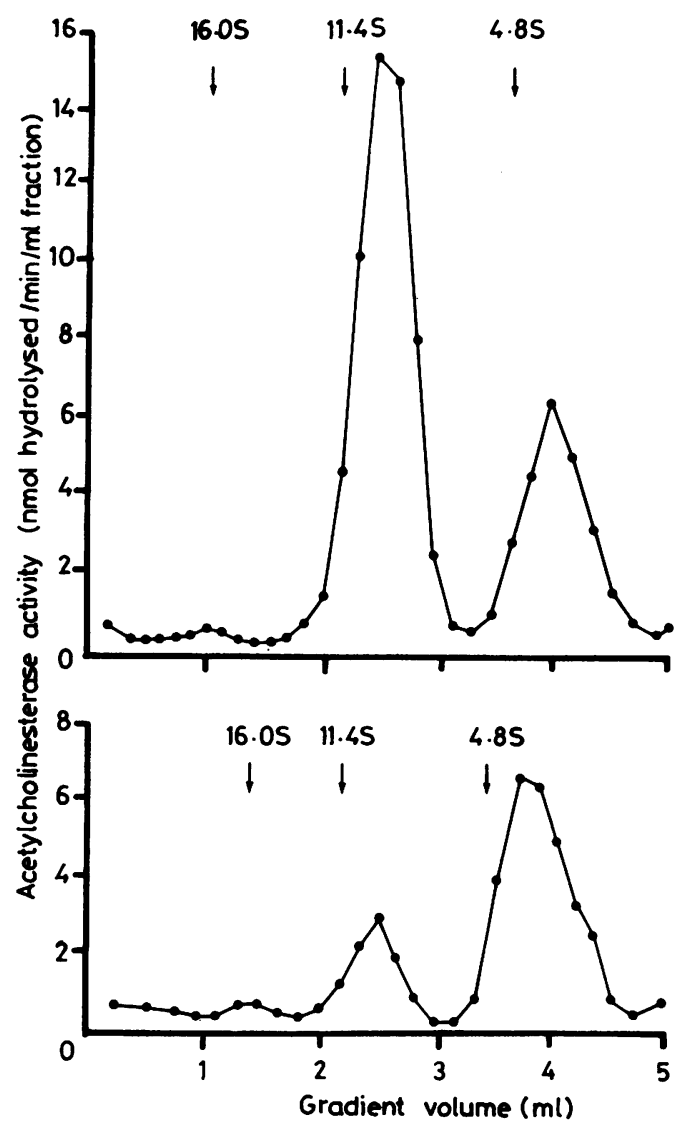

Fig 1 Acetylcholinesterase molecular forms, separated by sucrose density gradient centrifugation ${ }^{18}$ (density decreasing with increasing volume), in parietal cortex $(40 \mathrm{mg}$ ) from $a$ typical control (above) and demented case of Parkinson's disease (below). The selective and extensive loss of the intermediate, 10S, molecular form was typical of results in 3 normal and the 3 Parkinsonian dementia cases analysed, in which total, integrated peak activities (units $=$ nmol $/ \mathrm{min}$ ) were, respectively: $4.56 \pm 1.60$ and $4.60 \pm 0.66(3.7 \mathrm{~S}$ form); $9.56 \pm 0.15$ and $1.56 \pm 0.23$ (10S form); $0.28 \pm$ 0.01 and $0.19 \pm 0.12$ (16S form). Positions of 3 standard sedimentation velocity markers ( $\beta$-galactosidase (16.0S), catalase $(11.4 S)$ and alcohol dehydrogenase $(4 \cdot 8 S)$ ) are indicated by the arrows.

case was examined. There was, however, no correlation between the plaque numbers and activities of CAT or AChE in either the Parkinsonian cases or the normal and Parkinsonian groups together $(\mathrm{r}$ values were, respectively, $-0 \cdot 33, \mathrm{n}=14$ and $-0 \cdot 31, \mathrm{n}$ $=22$ for temporal cortex CAT and 0.14 and -0.05 for temporal cortex $\mathrm{AChE}$ ). In contrast, in the seven cognitively impaired Parkinsonian cases with available recent mental test scores, there was a tendency for CAT activities in the temporal cortex to be positively correlated with test scores $(r=0.84 p<z$ 0.02 ). These data on the relation between CAT activities and mental test scores are illustrated in fig 3 in which previous data, ${ }^{3}$ collected from cases with depression or Alzheimer-type dementia, are also incorporated. Figure 3 demonstrates that while there was a positive overall correlation between test scores and CAT, the relationship was nonlinear. Thus, a considerable loss (over $65 \%$ of the normal) of CAT was seen as the scores fall from normal (37) to around 20 but only a minor further reduction $\stackrel{\vec{\rho}}{\mathcal{O}}$ (under 20\%) as test scores dropped further towards 0 zero. Parkinsonian patients, therefore, with only 흐 slight or moderate cognitive impairment may have $\frac{\bar{m}}{\frac{D}{\sigma}}$ considerable loss of cortical CAT and Meynert $\mathbb{\mathbb { Q }}$ neurons (see below).

Although cortical cholinergic activities in the Parkinsonian group were not apparently related to the $\vec{\circ}$ presence of senile plaques in the cortex, they were $\overrightarrow{\vec{\omega}}$ clearly related to the numbers of neurons in the $\omega^{\sigma}$ Meynert nucleus (table 1). There was in the cognitively impaired Parkinsonian subgroup, where neuron numbers were available, an average $72 \% \stackrel{\vec{\infty}}{\circ}$ neuron loss-similar in extent to the cortical CAT i loss, ranging from $66-78 \%$ in the different areas. If $A$ the cognitively unimpaired subgroup, neuron loß $\vec{\omega}$ was less (average of $17 \%$ ) in keeping with the les extensive cortical CAT reductions in this group ranging from 11-60\%. In the Parkinsonian group as a whole (including one case of combined Parking son's and Alzheimer's disease) there were correlas. $\vec{\varphi}$ tions between the number of neurons in the nucleus of of Meynert and neocortical CAT activities in all areas except parietal cortex. This trend was most marked for temporal cortex (fig 4 ) where the correlation was highly significant $(\mathrm{p}<0.001)$ for the Parkinson cases $(r=0.93, n=8)$. In the cases of $\frac{0}{D}$ Alzheimer's disease no such trend was apparent (fig $\varrho$ 4). There was in this moderately advanced series of $\overrightarrow{\overrightarrow{0}}$ Alzheimer cases only a slight loss of neurons from the Meynert nucleus compared with the control group, despite considerable reductions in cortical CAT, ranging from $59-82 \%$ in the different areas and in the four cases with available neuronal counts the correlation with temporal cortical CAT was near $\overline{0}$ zero $(r=0 \cdot 04)$. Although tissue atrophy no doubt $\frac{3}{6}$. occurs in areas affected by neuronal degeneration $ᄋ$ this was not (as judged by the length of the region $₹$ containing identifiable Meynert neurons) in excess 웅 of $25 \%$ in the Alzheimer series and would not be $D$ expected to alter the non-significance of this correlation. In future studies neuronal numbers in possible subgroups ${ }^{1920}$ of the basal forebrain cholinergic cells $\sigma$ and the extent of tissue shrinkage should no doubt $\mathbb{O}$ be assessed together to obtain a more accurate index $\underset{\mathrm{W}}{ }$ 

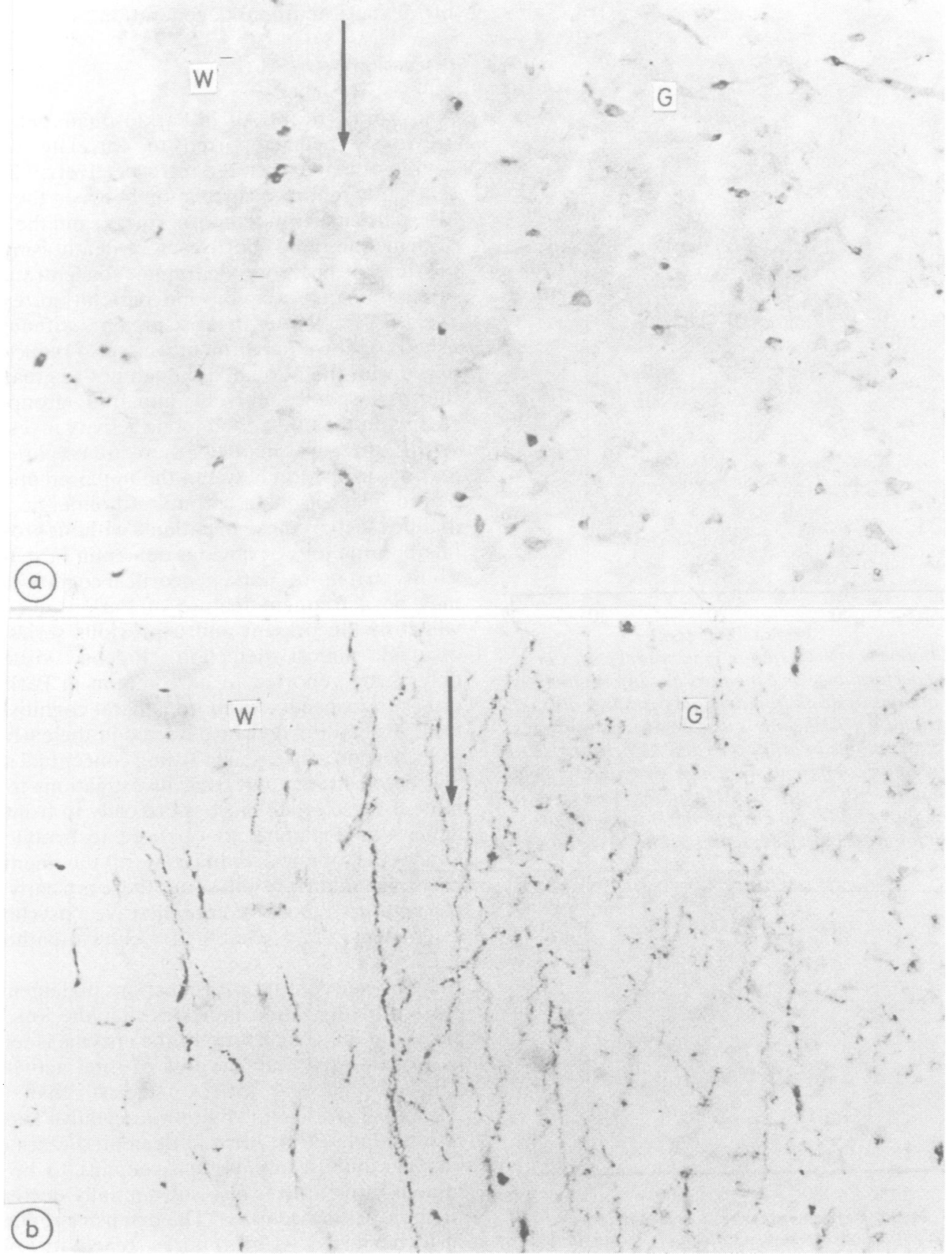

Fig 2 Acetylcholinesterase (AChE) histochemically demonstrated in the superior temporal gyrus from a demented (a) and non-demented (b) case of Parkinson's disease. In (b) AChE-positive axonal cholinergic fibres are present in both white matter $(W)$, the grey/white junction (arrow) and the deep cortical grey matter layers $(G)$. In the grey matter of a typical demented Parkinsonian case (a) such fibre staining is absent (upper cortical layers not illustrated) although reactivity is still present in some pyramidal neurons and was observed in occasional white matter fibres. In both cases snap frozen tissue from the superior temporal gyrus was cryostat sectioned $(20 \mu \mathrm{m})$, post-fixed in formal calcium and reacted histochemically for AChE using a silver intensification technique (see ref 17). Mag $\times 2002 a$ and $2 b$. 


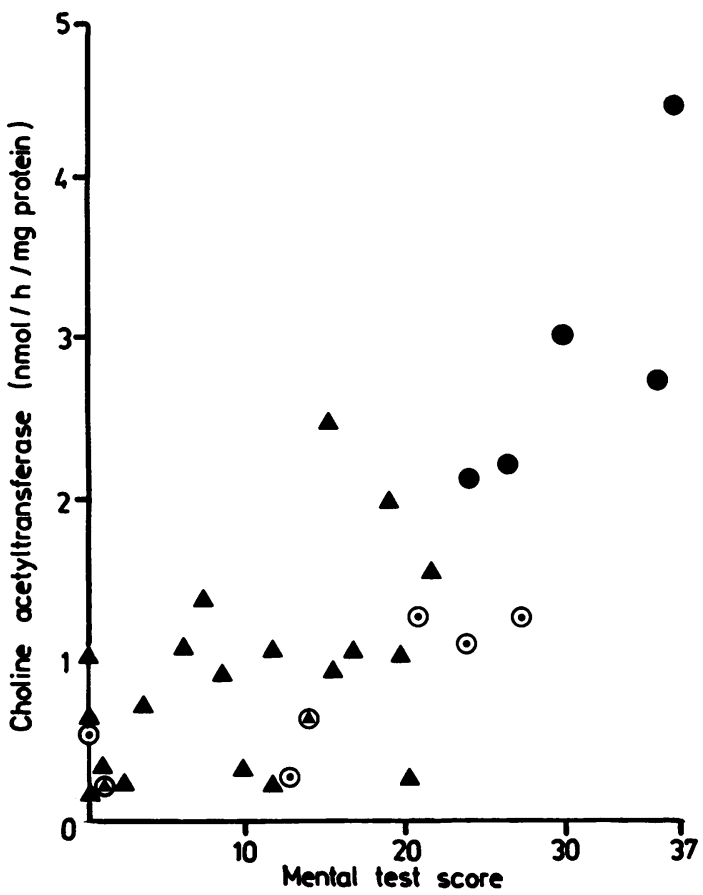

Fig 3 Choline acetyltransferase in temporal cortex in relation to performance on a memory and information test ${ }^{14}$ within 6 months of death in individual cases (see also ref 3) of depression (O); Alzheimer's disease ( $\Delta$ ); Parkinson's disease $(\odot)$; combined Parkinson's and Alzheimer's disease (A). Correlation coefficients were highly significant for the entire group $(r=0.76, p<0.001)$ and for those cases with test scores above $20(r=0.84, p<0.01)$ but only just significant for those cases with scores below $20(r=0.47, p$ $<0.05)$.

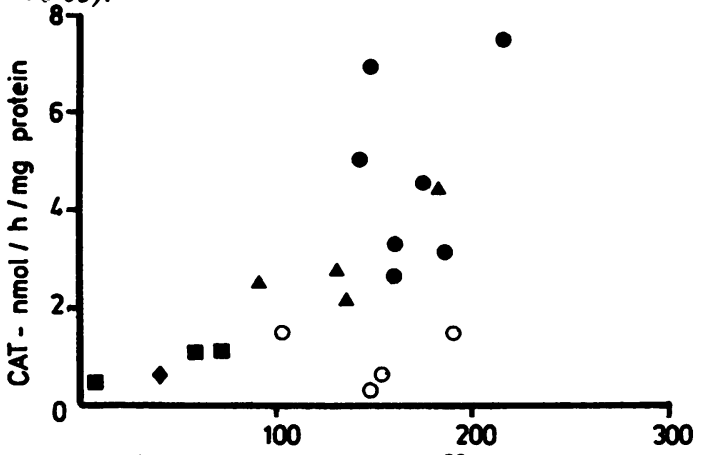

Mean neuron number $120 \mu$ section

Fig 4 Relation between neuron numbers in the nucleus of Meynert and choline acetyltransferase (CAT) in temporal cortex of individual normal cases (O); cases of Parkinson's disease with $(\square)$ and without $(\Delta)$ dementia; $a$ combined case of Parkinson's and Alzheimer's disease ( $\bullet$ ) and cases of Alzheimer's disease (O). The correlation was not significant in the group as a whole $(r=0.46,0.1>p>0.05)$ but was highly significant $(r=0.93, p<0.001)$ in the Parkinsonian cases alone. of Meynert neuronal degeneration.

\section{Discussion}

A loss of cortical CAT in Parkinsonian patients has previously been reported to correlate with the degree of dementia rated retrospectively. ${ }^{10}$ The present study reports a correlation between the enzyme loss, particularly in temporal cortex, and the severity of dementia rated shortly before death using a simple test of memory, learning, concentration and orientation. In occipital and parietal cortex, however, CAT activities in those patients without established cognitive impairment were also reduced compared with the normal, although not as greatly as in the assessed cognitively impaired group. With respect to the other cholinergic activity investigated, AChE, there was in one of these areas (parietal cortex) no distinction between the impaired and unimpaired Parkinsonian group. Cholinergic abnormalities such as these in patients without gross mental abnormalities or obvious dementia raise the possibility that more subtle neocortical cognitive deficits may be a frequent feature of Parkinson's disease which in the present and a previous series" have escaped clinical detection. Indeed, visuospatiaf defects are reported to be common in Parkinson'? disease irrespective of more general cognitive func $\unrhd$ 을 tion. ${ }^{5}$ Regarding deficits detected in the early stage $\rightarrow$ of Parkinson's disease in shifting conceptual sets, ${ }^{21}$ is will be of interest in future investigations to detere mine if these relate more specifically to frontal lobe्ष. $\vec{\circ}$ deficits in dopamine as opposed to acetylcholine o o Given the obvious limitations of the mental test employed in the present series there is clearly a need to conduct more comprehensive psychological assessment in combined clinical-pathological studies.

With respect to $\mathrm{AChE}$ reductions in dementia, the present investigation indicates that the loss of one particular molecular form of the enzyme is relatively more extensive than the loss of total activity. The data on parietal cortex suggest that, as in Alzheimer's disease, ${ }^{18}$ there is a selective loss of the intermediate (10S) form in demented cases of Parkinson's disease although it remains to be determined if this form is also substantially decreased in the non-demented cases. The extensive reduction in histochemical AChE fibre reactivity in the demented Parkinsonian cases is explicable in terms of loss of the predominantly membrane-bound ${ }^{18} 10 \mathrm{~S}$ form which is probably present in cholinergic axonal processes. In general, there is no biochemical evidence to suggest that the cortical cholinergic abnormality differs functionally in the two dementing disorders and in both instances it probably reflects 
degeneration of cholinergic afferent processes (see below).

The extent of the cortical cholinergic abnormalities in cognitively impaired Parkinsonian patients, as judged by the reductions in CAT, is similar to that seen in Alzheimer's disease. This is of considerable interest since dementia in the latter disorder is generally more severe than that seen in Parkinson's disease. There are at least two possible explanations for this trend, which is illustrated (fig 3) by the much lower correlation between CAT activities and mental test performance below a score of approximately 20 . In the first place, an abnormality of the cortical cholinergic system or loss of Meynert neurons may be associated with only a moderate deficit in cognitive function-as seen in some Parkinsonian cases and early Alzheimer-type dementia-but not with the severe mental deterioration and established dementia which eventually occurs in Alzheimer's disease. Alternatively fluctuations in CAT enzymatic activity may not accurately reflect functional physiological changes in cholinergic neurotransmission. Reductions of up to $50 \%$ may occur, as in apparently mentally normal Parkinsonian cases, in the absence of alterations in synaptic transmission. Further analyses of the clinical deficits in Parkinson's and Alzheimer's disease in relation to not only cholinergic but also other transmitter activities may help to resolve this issue. In addition the influence of drug treatment and anticholinergic therapy which has not been considered in the present study, may need to be assessed in relation to the possible effects of levodopa on CAT and $\mathrm{AC}$ ChE.

From the therapeutic point of view patients with Parkinson's disease showing cognitive impairment and cholinergic deficits may represent the optimum clinical group in which to assess the effects of cholinergic replacement or agonist therapy on countering cognitive deficits due to cortical cholinergic deficiency. In this group the relative absence of neocortical neuropathological abnormalities contrasts with the situation in Alzheimer's disease, in which a cholinergic deficit is accompanied by extensive cortical neuropathological abnormalities (plaques and tangles) which may mask any potential improvement in cognitive function brought about by cholinomimetic therapy. Future electrophysiological studies should establish whether reported EEG abnormalities (random diffuse slow activity) in Alzheimer's disease and presenile dementia ${ }^{22}{ }^{23}$ and some cases of Parkinson's disease, ${ }^{24}$ result from impaired cortical cholinergic function. Such a concept would find support in the reduced cortical electroencephalic activity observed in rats with basal forebrain cholinergic lesions. ${ }^{25}$
Although it is uncertain if the cholinergic deficit of Alzheimer-type dementia is causally or directly related to the presence of cortical plaques and tangles, it is clear from this series that the cortical cholinergic deficit in many cases of Parkinson's disease is not explicable in terms of the development of cortical Alzheimer-type pathology. The most likely explanation for the extensive reductions in cortical CAT in Parkinson's disease is degeneration of axonal processes associated with the extensive loss, reported here and elsewhere ${ }^{1112}$ of neurons in the Meynert nucleus which supplies the neocortex with at least the majority of its cholinergic input. Whilst this nucleus is generally severely affected in presenile cases of Alzheimer's disease, ${ }^{26}$ the cell loss in senile cases is only moderate ${ }^{27}$ and indeed was only slight in the four relatively less advanced senile cases of the present series. Despite this less extensive cholinergic cell body loss, cortical CAT activity in these Alzheimer cases was generally as extensively reduced as in the Parkinsonian group which showed a $70 \%$ neuron loss. It can therefore be suggested that cortical cholinergic abnormalities in Parkinson's disease reflect the primary degeneration of neurons in the nucleus of Meynert. This may occur in an analogous, although unknown, fashion to the degeneration of pigmented nigral neurons. In Alzheimer's disease the extensive cortical CAT reductions in conjunction with normal numbers of subcortical perikarya indicates, as argued previously, ${ }^{27}$ a "dying back" of cholinergic afferentsprobably resulting from primary cortical pathology. In this context it is of interest to note that serotonergic-S2 receptor binding is reduced in Alzheimer-type ${ }^{28}$ but not Parkinsonian dementia, ${ }^{29}$ indicative, perhaps, of cortical abnormalities confined to the former disease.

The two cases of Parkinson's disease who presented primarily with a dementing syndrome illustrate points of clinical and neuropathological interest. Psychiatrically, their presentation included neocortical cognitive deficits (the triad of aphasia, apraxia and agnosia) usually associated with Alzheimer's disease and attributed to "parietal lobe" cortical pathology. This series demonstrates that in some patients aphasia, apraxia and agnosia may also be a feature of the cognitive impairment seen in Parkinson's disease, and that in this respect the clinical presentation of these cases may mimick the dementia seen in Alzheimer's disease. In such cases the diagnosis of Parkinson's disease may not be obvious, especially if its usual presenting features of tremor, akinesia and rigidity are minimal. Such diagnostic difficulties have undoubtedly extended to combined clinical and neuropathological studies, in which neuropathological examination of patients 
dying with suspected Alzheimer's disease has identified a small proportion lacking typical Alzheimer-type cortical changes. ${ }^{16}$ Examination of the substantia nigra in such cases is essential to identify, or exclude, Parkinson's disease. Establishing the neurochemical or neuropathological basis of the "parietal lobe" cognitive deficits seen in these cases of Parkinson's disease ideally requires investigation in a larger series. Neurochemically, however, it may be suggested that a neocortical cholinergic deficit is associated with parietal lobe symptomatology and that the deficit is reflected neuropathologically by loss of neurons in the nucleus of Meynert. A further interesting neuropathological feature in these cases was the presence of a neocortical senile plaque density in the upper normal range (14 plaques per $1.3 \mathrm{~mm}^{2}$ ) in the absence of neocortical tangles and of significant Alzheimer type pathology in the hippocampal formation. A similar subgroup of Parkinsonian patients with a moderate neocortical plaque density has been identified in a larger neuropathological series (Tomlinson and Perry, in preparation) and whilst the neuropathological criteria for diagnosing Alzheimer's disease, including the presence of neocortical tangles, were not present it remains possible that this density of senile plaque formation (either independently or in association with the cholinergic deficit; see above) contributes to the features of "parietal lobe" cognitive impairment. At a more basic pathogenetic level in this Parkinsonian subgroup, it remains to be determined if the aetiological factor(s) which cause or are associated with Parkinson's disease (including abnormalities in subcortical nuclei which project to the striatum and cortical regions) are responsible for inducing plaque but not tangle formation in the neocortex. The formulation of a hypothesis linking plaque formation with other pathological features of the disease however, such as Meynert neuron loss, does not readily account for the absence of a raised plaque density in the majority of Parkinsonian cases, with or without cognitive impairment.

In conclusion, the present investigation suggests a close correlation between mental impairment (or at least some aspects of the impairment) in Parkinson's disease and declining cholinergic activity, reflected by both cortical biochemical activities and subcortical neuronal population density. Other neuronal systems projecting to the cortex from various subcortical nuclei (such as the raphe and locus coeruleus) which also degenerate in Parkinson's disease $^{30}$ should also be investigated in connection with the cognitive impairment of this disease.

The financial support of the Medical Research Council and excellent technical assistance of
Dorothy Irving, Andrew Brown, Judith Thompson and Christine Lowthian are gratefully acknowledged.

\section{References}

${ }^{1}$ Deutsch JA. The cholinergic synapse and the site of $\Omega$ memory. In: Deutsch JA ed. The Physiological Basis of Memory, New York, Academic Press, 1973:59-74.

${ }^{2}$ Drachman DA, Leavitt J. Human memory and the cholinergic system a relationship to ageing? Arch Neurol 1974;30:113-21.

${ }^{3}$ Perry EK, Tomlinson BE, Blessed G, Bergmann K, Gibson PH, Perry RH. Correlation of cholinergic abnormalities with senile plaques and mental test scores in senile dementia. Br Med J 1978;2:1457-9.

4 Wilcock GK, Esiri MM, Bowen DM, Smith CT. Correla- ڤ tion of cortical choline acetyltransferase activity with the severity of dementia and histological abnormalities. J Neurol Sci 1982;57:407-17.

${ }^{5}$ Mayeux R. Depression and dementia in Parkinson's disease. In: Marsden $\mathrm{CD}$ and Fahn $\mathrm{S}$ eds. Movement Disorders, London. Butterworth 1981:75-95.

- Alvord EC, Forno LS, Kusske JA, Kauffman RJ, ? Rhodes JS, Goetowski CR. The pathology of Parkin $\infty$ sonism: a comparison of degenerations in cerebra or cortex and brainstem. In: McDowell $F$ and Barbeau $\stackrel{\oplus}{\oplus}$ eds. Second Canadian-American Conference on Pa $\Omega_{\bar{D}} \omega$ kinson's Disease (Advances in Neurology, Vol. $5 \$$ 음 New York, Raven 1974:175-93.

' Hakim AM, Mathieson G. Dementia in Parkinson's di\& ease: a neuropathologic study. Neurology (Minneap 1979; 29: 1209-14.

' Lloyd KG, Mohler H, Heitz PH, Bartholini G. Distribi tion of choline acetyltransferase and glutamate decar boxylase within the substantia nigra and other regions from control and Parkinsonian patients. J Neurochem 1975;25: 789-95.

${ }^{9}$ Reisine TD, Fields JZ, Yamamura HI, et al. Neurotransmitter receptor alterations in Parkinson's disease. Life Sci 1977;21:335-44.

${ }^{10}$ Ruberg M, Ploska F, Javoy-Agid F, Agid Y. Muscarinic $\overrightarrow{\overline{0}}$ binding and choline acetyltransferase activity in Parkinsonian subjects with reference to dementia. Brain Res 1982;232:129-39.

" Candy JM, Perry RH, Perry EK, et al. Pathological changes in the nucleus of Meynert in Alzheimer's and Parkinson's diseases. J Neurol Sci 1983;59:277-89.

12 Whitehouse PJ, Hedreen JC, White CL, Price DL. Basal forebrain neurons in dementia of Parkinson's disease. Ann Neurol 1983;13:243-8.

${ }^{13}$ Perry RH, Tomlinson BE, Candy JM, et al. Cortical 3 cholinergic deficit in mentally impaired Parkinsonian $\mathrm{O}$ patients. Lancet 1983; 2:789-90.

${ }^{4}$ Blessed G, Tomlinson BE, Roth M. The association $\frac{7}{0}$ between quantitative measures of dementia and of senile change in the cerebral grey matter of elderly $\mathrm{N}$ subjects. Br J Psychiatry 1968;114:797-811.

15 Tomlinson BE, Blessed G, Roth M. Observations on the $\mathbb{O}$ brains of non demented old people. J Neurol Sci N 
1968; 7:331-56.

${ }^{16}$ Tomlinson BE, Blessed G, Roth M. Observations on the brains of demented old people. J Neurol Sci 1970;11:205-42.

17 Perry RH, Candy JM, Perry EK, Thompson J, Oakley $\mathrm{AE}$. The substantia innominata and adjacent regions in the human brain: histochemical and biochemical observations. J Anat 1984; 138:713-32.

${ }^{18}$ Atack JR, Perry EK, Bonham JR, et al. Molecular forms of acetylcholinesterase in senile dementia of Alzheimer-type: selective loss of the intermediate (10S) form. Neurosci Lett 1983;40:199-204.

${ }^{19}$ Brochlaus H. Zür feineren Anatomie der Septum und des Striatum J Psychol Neurol 1942;51:1-56.

${ }^{20}$ Mesulam MM, Mufson EJ, Levey AI, Wainer BH. Cholinergic innervation of cortex by the basal forebrain: Cytochemistry and cortical connections of the septal area, diagnonal band nuclei, nucleus basalis (substantia innominata), and hypothalamus in the rhesus monkey. J Comp Neurol 1983;214:170-97.

${ }^{21}$ Lees AJ, Smith E. Cognitive deficits in the early stages of Parkinson's disease. Brain 1983; 106:257-70.

${ }^{22}$ Letemendia F, Pampliglione G. Clinical and electroencephalographic observations in Alzheimer's disease. J Neurol Neurosurg Psychiatry 1958; 21:167-72.

${ }^{23}$ Gordon EB, Sim M. The EEG in presenile dementia. $J$ Neurol Neurosurg Psychiatry 1967;30:285-91.
${ }^{24}$ England AC, Schwab RS, Peterson E. Electroencephalogram in Parkinson's Syndrome. Electroencephalogr Clin Neurophysiol 1959;11:723-31.

${ }^{25}$ Lo Conte G, Casamenti F, Bigl V, Milaneschi E, Pepeu G. Effect of magnocellular forebrain nuclei lesions on acetylcholine output from the cerebral cortex, electrocorticogram and behaviour. Arch Ital Biol 1982; 120: 176-88.

${ }^{26}$ Whitehouse PJ, Price DL, Struble RG, Clark AW, Coyle JT, De Long MR. Alzheimer's disease and senile dementia-loss of neurons in the basal forebrain. Science 1982;215:1237-9.

${ }^{27}$ Perry RH, Candy JM, Perry EK, et al. Extensive loss of choline acetyltransferase activity is not reflected by neuronal loss in the nucleus of Meynert in Alzheimer's disease. Neurosci Lett 1982;33:311-5.

${ }^{28}$ Cross AJ, Crow TJ, Johnson JA, et al. Studies on neurotransmitter receptor systems in neocortex and hippocampus in senile dementia of the Alzheimer-type. $J$ Neurol Sci 1984;64:109-17.

${ }^{29}$ Perry EK, Perry RH, Candy JM, et al. Cortical serotonin-S2 receptor binding abnormalities in Alzheimer's disease-comparison with Parkinson's disease. Neurosci Lett 1984;51:353-7.

${ }^{30}$ Forno LS. Pathology of Parkinson's disease. In: Marsden $\mathrm{CD}$ and Fahn S, eds. Movement Disorders, London. Butterworth, 1981:25-40. 